\title{
Provenance Variation on Early Survival Rate and Growth Performance of Oxytenanthera abyssinica (A. Rich.) Munro Seedlings at Green House: An Indigenous Lowland Bamboo Species in Ethiopia
}

\author{
Tinsae Bahru (D), ${ }^{1,2}$ Berhane Kidane, ${ }^{3}$ and Yigardu Mulatu ${ }^{3}$ \\ ${ }^{1}$ Department of Silviculture, College of Forestry, Nanjing Forestry University, China \\ ${ }^{2}$ Central Ethiopia Environment and Forest Research Center (CEE-FRC), Ethiopia \\ ${ }^{3}$ Ethiopian Environment and Forest Research Institute (EEFRI), Ethiopia \\ Correspondence should be addressed to Tinsae Bahru; batinsae@yahoo.com
}

Received 21 June 2018; Revised 5 October 2018; Accepted 7 November 2018; Published 9 December 2018

Academic Editor: Arianna Azzellino

Copyright (c) 2018 Tinsae Bahru et al. This is an open access article distributed under the Creative Commons Attribution License, which permits unrestricted use, distribution, and reproduction in any medium, provided the original work is properly cited.

\begin{abstract}
Background. Lowland Bamboo (O. abyssinica) is an indigenous multipurpose species in Ethiopia and endemic to Africa. Aims. The present study was aimed at investigating provenance variation on early survival rate and growth performance of $O$. abyssinica seedlings so as to obtain suitable provenance for production of high quality seedlings. Methods. Seeds were collected from Pawe and Sherkole districts. Following raise of seedlings data on survival count, culm height, root collar diameter (RCD), number of leaves, and biomass were recorded. Results. Pawe provenance had slightly higher survival rate (91\%). Except seedlings RCD, rhizomes length, and roots fresh and dry weights, higher mean values of other morphological parameters were recorded in Sherkole provenance. Biomass of leaves and culms was higher in Shekole provenance, while root biomass was exceeded by the Pawe provenance. However, significant variations $(\mathrm{P}<0.05)$ between provenances were observed in RCD, rhizomes length, weight of fresh culms, and fresh and dry root system. Seedlings growth parameters (height and RCD) were positively and significantly correlated with Biomass variables and hence could be considered as better evaluation criteria for seedling quality at green house. Conclusion. Sherkole provenance should be considered for raising O. abyssinica seedlings at green house.
\end{abstract}

\section{Introduction}

Bamboo belongs to the subfamily Bambusoideae and family Gramineae or Poaceae $[1,2]$. There are at least 90 genera [3] and more than 1,575 Bamboo species [2] are distributed throughout the world. Nowadays, there are two indigenous [4] and 27 introduced [5] Bamboo species are found in Ethiopia. As a result, Ethiopia has a huge amount of Bamboo resource in total area coverage in Africa. It covers 1.44 Million ha [6], i.e., about $7 \%$ of the world total and $67 \%$ of the African Bamboo forest area [4]. Among these, O. abyssinica (lowland Bamboo) is an indigenous Bamboo species in Ethiopia and endemic to Africa [4]. In Ethiopia, the species is found in lowland regions of western and northwestern parts of Ethiopia [7] in Tigray, Gonder, Gojam, and Welega Regions
[1]. But, recent study conducted by Zhao et al. [6] confirmed that the species is distributed mainly in BenishangulGumuz, western part of Amhara and Oromia Regions. In addition, it is widespread in African continent mainly in Ethiopia, Eritrea, Sudan, South Sudan, Uganda, Tanzania, Central African Republic, Republic of Congo, Democratic Republic of Congo, Senegal, Guinea, Sierra Leone, Cote d'Ivoire, Ghana, Togo, Benin, Nigeria, Cameroon, Angola, Zambia, Malawi, Zimbabwe and Mozambique [8], and Asian continent such as India [3, 9], and Vietnam [9]. It is a solid woody clump forming Bamboo growing up to a height of 3-13 $\mathrm{m}$ and a diameter of 5-10 cm [1]. It grows in Savanna woodland, along the river valleys and spreads around on the hills, often forming extensive stands $[1,6]$ at the altitudes ranging from 540 [6] to 1,800 $\mathrm{m}$ above sea level (a.s.l.) [1]. The 
TABLE 1: Geographic locations and climatic conditions of O. abyssinica seed provenances at Benishangul-Gumuz Regional State, western Ethiopia.

\begin{tabular}{lccccc}
\hline Provenance & District & $\begin{array}{c}\text { Geographical location } \\
(\text { Lat. \& Long.) }\end{array}$ & $\begin{array}{c}\text { Altitude } \\
(\mathbf{m} \text { a.s.l.) }\end{array}$ & Rainfall (mm) & $\begin{array}{c}\text { Temperature } \\
\left({ }^{\circ} \mathbf{C}\right)\end{array}$ \\
\hline Pawe & Pawe & $11^{\circ} 20^{\prime} \mathrm{N} ; 36^{\circ} 20^{\prime} \mathrm{E}$ & 990 & 1,587 & $16.3-32.6$ \\
Sherkole & Sherkole & $10^{\circ} 40^{\prime} \mathrm{N} ; 34^{\circ} 36^{\prime} \mathrm{E}$ & 875 & $900-1,200$ & $10.8-42$ \\
\hline
\end{tabular}

species annual rainfall ranges from about 700 to $1,000 \mathrm{~mm}$, which is concentrated over a period of three to four months with the mean annual temperature of above $30^{\circ} \mathrm{C}$ [10]. The species can grow at a minimum temperature of $-1^{\circ} \mathrm{C}$ and prefers moist conditions along waterways [3]. Based on our observation $O$. abyssinica can grow in full sunlight and it is also drought resistant and may be deciduous in hot and dry conditions. The species is easily adaptable to poor soils and could be used to establish buffer zone for desert areas [10]. Consequently, it is one of the most promising Bamboo species in rehabilitation of degraded areas and hence suitable to replace the declining forest resources in Ethiopia.

Although Bamboo has higher biomass production, shorter rotation and fastest growing behavior, agricultural expansion and/or shifting cultivation, and construction and high fuel wood demand, human settlement, and uncontrolled or accidental forest fire are the major bottlenecks for Bamboo resource in Ethiopia. Other factors include limited availability and poor storage of seeds [11, 12] and seedlings, mass flowering and death of Bamboo, and longer flowering intervals and unpredictable flowering time [13]. In the same way, the traditional management system in private Bamboo plantation and even mismanagement of community and/or state owned forests further aggravate the problem of resource depletion. More emphasis is also given to economic returns instead of prior management and conservation of Bamboo. Collectively, more attention is not given by farmers as well as foresters in promoting various Silvicultural practices of either indigenous or introduced Bamboo species [14, 15]. Some of these are hampered regeneration, mismanagement of stand density and age structure, limited soil loosening and fertilizer application, and inappropriate harvesting techniques. For instance, out of nearly $6.5 \%$ of the total Bamboo forest in Ethiopia, about 2.2\% Bamboo plantation in the highlands [15] might be an indication of such limitation on Bamboo sustainable management and utilization. Therefore, application of silvicultural practices in Bamboo forest and its sustainable use needs very urgent call. During recent years, interest has also been increased to ecological restoration of especially degraded areas through reforestation and afforestation programmes. In order to capitalize on advances made in such programmes, suitable provenance (original geographic source of the seed) selection and successful establishment of $O$. abyssinica seedlings at field is very important. Furthermore, evaluating seedlings outplanting performance at field condition must be an integral part of selecting the provenance with higher adaptation potential. With this end, raising high quality and large number of $O$. abyssinica seedlings for small-scale and large-scale plantation development in Ethiopia from recommended provenance at green house is reasonable. This is because provenance variation is directly associated with a variation in their adaptation potential at a particular area. Recent studies have also shown that provenance variation affects the functional characteristics of seedlings and their field performance. This demonstrates high quality seedlings show substantial survival and growth performance, thus expressing their full establishment and adaptation potential at field condition. Such difference in adaptation potential, in turn, can be demonstrated in various morphological as well as physiological characteristics [16]. Eventually, the research described that this is directly related to a limited probability of inbreeding between provenances and thereby causes always genetic variations. Suitable provenance saves site maintenance costs and reduces the subsequent rotation period. This further enhances the financial returns on overall future reforestation and afforestation programmes at large-scale plantation development. It also diversifies source of income, creates job opportunity, and improves people's livelihoods through small-scale plantation. Collectively, this study on early survival rate and growth performance of the different provenances of Bamboo at green house stage will help to evaluate the suitability of Bamboo provenances for promotion purposes. This further contributes to selection of better provenance for selected areas so as to achieve adaptable seedlings at field condition. Therefore, the present study was aimed at examining the hypothesis: provenance variation has a significant effect on early survival rate and growth performance of O. abyssinica seedlings at green house.

\section{Materials and Methods}

2.1. Description of the Study Site. The experiment was conducted at Central Ethiopia Environment and Forest Research Center (CEE-FRC). The green house is located in the Highland Agro-ecology at the altitude of $2,368 \mathrm{~m}$ a.s.l. between $37^{\circ} 04^{\prime} \mathrm{E}$ Latitude and $09^{\circ} 96^{\prime} \mathrm{N}$ Longitude. Addis Ababa has a mean annual rainfall of $1,000 \mathrm{~mm}$ and a mean monthly temperature of $20^{\circ} \mathrm{C}$.

Seeds of $O$. abyssinica were collected from two provenances of Benishangul-Gumuz Regional State, western Ethiopia. These provenances were Pawe and Sherkole districts. The elevation of Pawe is $990 \mathrm{~m}$ a.s.l. between $11^{\circ} 20^{\prime} \mathrm{N}$ latitude and $36^{\circ} 20^{\prime} \mathrm{E}$ longitude (Table 1). It has a mean annual temperature of $24.52^{\circ} \mathrm{C}$ and an average annual rainfall of $1,773 \mathrm{~mm}$ [17]. In comparison, Sherkole is located between a latitude of $10^{\circ} 40^{\prime} \mathrm{N}$ and longitude of $34^{\circ} 36^{\prime} \mathrm{E}$ at $875 \mathrm{~m}$ altitudinal level. The mean annual temperature of Sherkole is 10.8 to $42^{\circ} \mathrm{C}$, while the total annual rainfall ranges from 900 tol,200 $\mathrm{mm}$ [18]. 
2.2. Seed Collection, Handling, and Processing. Seeds of $O$. abyssinica were collected in December from Pawe and Sherkole provenances. So as to ensure maximum genetic diversity and minimize inbreeding, seeds were collected from selected clumps of Bamboo stands at a distance of at least $100 \mathrm{~m}$ apart between them [19]. The collected fresh seeds were put in to perforated plastic bags and safely transported to CEE-FRC, EEFRI. Seeds which had been attacked by insects, physically damaged or decayed were excluded, extracted and cleaned in CEE-FRC seed processing room following the procedures by FAO [20]. Finally, the seeds were placed in perforated plastic bags and stored in cold room at $+5^{\circ} \mathrm{C}$ until the experiment was started as also partially applied by Baskin and Baskin [21]. This enables to maintain the viability of seeds and prevent from insect attack by reducing seed moisture $[20,22]$. Storing seeds at lower temperature further slow down the rate of physiological changes of many seeds [21]. Finally, the research also described that seeds were allowed to germinate at laboratory shortly after the collection of seeds, i.e., within a week.

2.3. Seedling Raising at Laboratory. Untreated O. abyssinica seeds, which have best germination percentage, were sowed at laboratory [11] on Petri-dishes. The filter paper was kept moist with distilled water as much as possible throughout the entire experimental period. In order to moisten the filter paper, water was added until the paper was saturated. Water was added to Petri-dishes if the water vapour was disappeared from the Petri-dishes. In turn, the Petri-dishes were holding on its side to allow excess water drained from the filter paper [21]. Once seeds were germinated, seeds were transplanted to laboratory plastic Trays (hereafter referred to as Trays), where sand served as germination medium. A seed was considered as germinated when the radicle was penetrated out from the seed coat and clearly appeared visually $[11,12]$.

2.4. Seedling Transplanting on Polyethylene Pots at Green House. Side by side, 100 polyethylene pots $(20 \mathrm{~cm}$ height and $20 \mathrm{~cm}$ diameter size) per provenance were prepared containing a mixture of 2 part forest soil and 1 part sand (2:1 ratio) to raise the seedlings. Accordingly, using a Completely Randomized Design (CRD) for each provenance, 100 polyethylene pots in 5 replications of 20 polyethylene pots each were established at green house. Following this, $100 \mathrm{O}$. abyssinica seedlings having 2-4 leaves were transplanted to polyethylene pots at green house from each provenance (i.e., Pawe and Sherkole districts). Since the provenances natural range is characterized by moist Kolla climatic condition (dry and hot areas), the experiment was conducted at CEEFRC green house instead of nursery so as to maintain relatively higher temperature. Seedlings survival ability in the green house was supervised until two weeks and the dead seedlings were replaced by other normal seedlings. Watering was done daily early in the morning and late in the evening when it is necessary. Other Silvicultural applications including weeding, hoeing, and inspection of pest and disease were further carried out regularly and when required.
2.5. Determining Early Survival and Mortality Rate of Seedlings. Survival count was conducted between two provenances at the age of two years after the completion of transplanting of seedlings in the polyethylene pots. The percentage survival of each provenance was calculated as the number of Bamboo seedlings survived at the age of two years divided by the total number of seedlings planted multiplied by 100 . On the other hand, the mortality rate of each provenance was calculated as the number of dead Bamboo seedlings at the age of two years divided by the total number of seedlings planted multiplied by 100 .

2.6. Evaluating Early Growth Performance of Seedlings. Green house data on growth performance of seedlings per provenance was recorded at the age of two years. These parameters included culm height, root collar diameter (RCD), and number of leaves for each seedling. Accordingly, culm height was measured using ruler in centimeter $(\mathrm{cm})$ from the soil surface to the tip of the Bamboo culm main axis, where the newly shoot was emerged. In case of seedling with more than one culm per clump, all culm heights per clump in each pot were recorded and the average culm height was recorded. Root collar diameter was measured using caliper in millimeter ( $\mathrm{mm}$ ) near the soil surface. Similar to culm height, for seedling with more than one culm per clump, all culms RCD per clump in each pot was measured separately and the average culm RCD was recorded. In line with this, the number of leaves in each Bamboo seedling was counted. Furthermore, detail practical observation, taking photos and interpretation, and thereby noting the various morphological and anatomical structures of the seedlings were conducted regularly.

2.7. Seedlings Biomass Estimation at Laboratory. Once the required data on early survival count and growth performance of seedlings were collected at the age of two years, preconditions for seedlings Biomass estimation (fresh and dry weight) were carried out. Hence, using systematic random sampling method, 30 seedlings per provenance were chosen and then each seedling was uprooted separately. During uprooting process, great care was taken to remove the soil from rhizome as well as primary and secondary roots developed from rhizomes. This is because the fine roots were cut and left into the soil so that it affected the length of rhizome and the fresh and dry weights. In turn, careful practical observation, recording information, and taking photos about the overall rhizome system were conducted thoroughly and included under the results and discussion part. Following this, seedling culm was cut at the soil surface using a sharp plant pruning scissor and separated from the rhizome. Data on the length of rhizome, number of clustered rhizomes developed from the main mother culm base, and biomass estimation was recorded. Accordingly, each seedling length of rhizome was measured from the base of mother culm to the tip of the longest rhizome and/or primary and secondary roots using ruler in $\mathrm{cm}$. The number of clustered rhizomes was counted for each seedling. Finally, each seedling leaf, culm, and rhizome was put separately in to 
TABLE 2: Mean values of seedlings early survival rate between two O. abyssinica provenances ( $\mathrm{n}=100$, mean \pm standard deviation (SD)).

\begin{tabular}{lccc}
\hline t-test & Pawe & Provenance & Sherkole \\
\hline Mean \pm SD & $0.91 \pm 0.29$ & $0.90 \pm 0.30$ & t-test for equality of means \\
t-value & & & 0.240 \\
Sig. difference $(\mathrm{P}<0.05)$ & & 0.811 \\
df $($ Degree of Freedom) & & 198 \\
\hline
\end{tabular}

the coded Manila Envelope (Kaki Wereket (Amharic)). Fresh weight of each seedling leaf, culm, and rhizome was measured using sensitive analytical balance in gram (g). Fresh weight was measured soon not to lose moisture and affect the weight. Following this, each seedling leaves, culms and rhizome with their respective envelopes placed into the dry-oven at a temperature of $73 \pm 2^{\circ} \mathrm{C}$ for 24 hours. Finally, envelops were removed out from the dry-oven and each seedling leaf, culm, and rhizome dry weight was measured as soon as possible not to absorb moisture and affect the weight. The process was continued until insignificant weight difference was observed between dry weights by measuring randomly drawn samples from small, medium, and large weights.

2.8. Statistical Data Analysis. Data were presented using percentages, figures and tables. In addition, statistical tests on seedlings early survival rate and growth performance parameters were subjected to independent-samples t-test using SPSS statistical software package version 20.0 (SPSS inc., IBM, USA) and the results were reported as Mean \pm Standard Deviation (SD). The statistical significance difference between treatments at $\mathrm{p}<0.05$ confidence interval was determined. Eventually, the survival and growth performance between provenances were evaluated using suitability index [23]. Thereafter, a two-tailed Pearson correlation analysis (SPSS Inc., IBM, USA) was performed to determine the relationships between Sherkole provenance seedlings growth and biomass variables. At the same time, linear regression equations and coefficient of determination $\left(\mathrm{R}^{2}\right)$ were developed for selected variables.

\section{Results}

The result of the experiment on $O$. abyssinica seedlings showed that seedlings successfully survived and had higher growth performance within two years at green house. Most of the seedlings developed 2-9 culms per clump. A culm is an erect Bamboo stem with branches, twigs, and foliage, while clump is an aggregate of a few to many culms that is developed from the rhizome. Its culm height attained up to $102 \mathrm{~cm}$, while the RCD thickened around $0.5 \mathrm{~mm}$. The present study on both provenances also clearly confirmed that its rhizome is characterized by the formation of clumps and has a short rhizome neck emerged from the mother culm base as shown in Figure 1. More fibrous root systems (rhizome roots developed from the node of the rhizome) were further associated with the rhizome system. Rhizome is the underground root-like stem of Bamboo. Therefore, $O$.

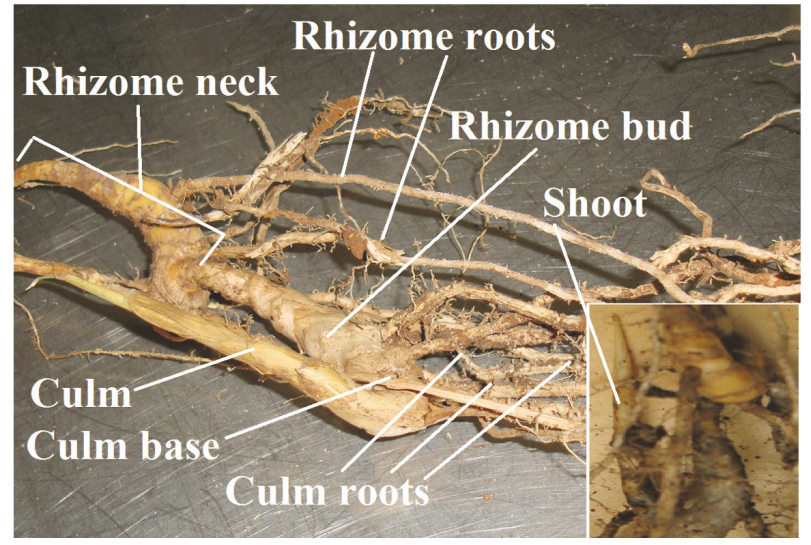

FIGURE 1: Short-necked pachymorph rhizome type of O. abyssinica seedlings at CEE-FRC (source: photo taken by Tinsae Bahru).

abyssinica seedlings had sympodial or pachymorph rhizome type due to the clumping nature of culms. Based on the present study, the survival, growth performance, and biomass of O. abyssinica was presented briefly as follows.

\subsection{Effects of Provenance on Seedlings Survival and Mortality} Rate. Both provenances successfully survived at green house. The survival rate of seedlings recorded at the age of two years varied from 90 to $91 \%$ between provenances (Table 2). Yet, Pawe provenance achieved slightly higher survival rate, which accounted for $91 \%$. In contrast to outperformed seedlings, only a few $O$. abyssinica seedlings were wilted and died over the entire experimental period, i.e., up to $10 \%$ of mortality rate. Despite this result the statistical independent-samples ttest for seedlings survival rate reported no considerable variation $\left(\mathrm{t}_{(198)}=0.24, \mathrm{P}=0.81\right)$ recorded between provenances.

\subsection{Effects of Provenance on Seedlings Early Growth Perfor-} mance Rate Determination. Data summary and analysis on early growth performance of $O$. abyssinica seedlings were presented in Table 3.

3.2.1. Culm Height . Each O. abyssinica seedling at green house demonstrated that the culm had internodes, nodes, culm sheath, and sheath scar. Each culm was separated into a serious of sections called internodes by culm nodes. Culm sheaths were developed on each culm node during the growth of seedlings and tightly overlapped and surrounded the culm internodes. Some seedlings in both provenances 
TABLE 3: Mean values of seedlings early growth performance parameters between two O. abyssinica provenances ( $\mathrm{n}=30$ or 100 , mean \pm standard deviation (SD)).

\begin{tabular}{lcccccc}
\hline Provenance & $\begin{array}{c}\text { Culm height } \\
(\mathbf{c m}), \mathbf{n}=\mathbf{1 0 0}\end{array}$ & $\begin{array}{c}\text { No of culms per } \\
\text { Bamboo clump, } \\
\mathbf{n = 1 0 0}\end{array}$ & $\begin{array}{c}\text { RCD (mm), } \\
\mathbf{n = 1 0 0}\end{array}$ & $\begin{array}{c}\text { No of leaves, } \\
\mathbf{n = 1 0 0}\end{array}$ & $\begin{array}{c}\text { Length of } \\
\text { Rhizomes, } \\
\mathbf{n = 3 0}\end{array}$ & $\begin{array}{c}\text { No of clustered } \\
\text { Rhizomes }(\mathbf{c m}), \\
\mathbf{n}=\mathbf{3 0}\end{array}$ \\
\hline Pawe & $61.18 \pm 18.36$ & $2.41 \pm 1.32$ & $0.26 \pm 0.07$ & $25.47 \pm 10.87$ & $31.80 \pm 7.59$ & $4.30 \pm 1.74$ \\
Sherkole & $67.07 \pm 15.78$ & $3.18 \pm 1.47$ & $0.25 \pm 0.07$ & $30.22 \pm 14.40$ & $28.67 \pm 6.68$ & $6.20 \pm 2.02$ \\
t-value & 2.313 & 3.725 & 0.841 & 2.506 & 1.697 & 3.894 \\
Sig. & 0.022 & 0.001 & 0.401 & 0.013 & 0.095 & 0.001 \\
\hline
\end{tabular}

possessed one or more number of branches developed from the main culm node (Figure 2). If the number of branches attached on each seedling was more than one culm node, the branches were attached in alternate positions on the culm node. Once the culm sheath was withered out and fallen off from each culm node, a scar, which is called sheath scar, was left around the culm node. Besides to these morphological structures, culms anatomy further showed that the nodes were solid, while the internodes were semisolid. Recorded data analysis on seedlings height indicated that the culm height between the two provenances ranged with the minimum and maximum values of 10 and $102 \mathrm{~cm}$, respectively. Pawe provenance scored the minimum culm height of $10 \mathrm{~cm}$ and the maximum height of $102 \mathrm{~cm}$. Sherkole provenance had a minimum and maximum culm height of 27 and $100 \mathrm{~cm}$, respectively. Sherkole provenance had better mean value of culm height $(67.07 \mathrm{~cm})$ over Pawe provenance (Table 3 ). The statistical t-test showed that there was a significant difference $(\mathrm{P}<0.05)$ in culms height between provenances. In contrast to culms height, the number of culms per clump of each polyethylene pot ranged from 2-9. Seedlings in Sherkole provenance developed more number of culms with a mean value of 3.18 than Pawe provenance (2.41). The two provenances also showed significant variation $\left(t_{(198)}=3.73, P=0.001\right)$ in terms of number of culms per clump. But, Pawe provenance had maximum number of culms per clump than Sherkole provenance, which accounted for 9 and 7 , respectively.

3.2.2. Root Collar Diameter (RCD). Green house data reported that the minimum and maximum values of RCD were 0.1 and $0.5 \mathrm{~mm}$, respectively between provenances. But, almost no considerable difference in culm diameter growth was observed as compared to culm height. A maximum value of $0.5 \mathrm{~mm}$ RCD was recorded in Pawe provenance followed by $0.4 \mathrm{~mm}$ in Sherkole provenance. Similarly, a mean value of $0.26 \mathrm{~mm}$ in Pawe provenance made better RCD seedlings performance than Sherkole provenance with a mean value of $0.25 \mathrm{~mm}$ (Table 3). However, no statistical significant difference $\left(\mathrm{t}_{(179)}=0.84, \mathrm{P}=0.40\right)$ in $\mathrm{RCD}$ was observed between provenances.

3.2.3. Number of Leaves. During the two years O. abyssinica seedlings lifespan at green house, the number of leaves in each seedling ranged from 5 to 82 . The leaves grew up from the culms sheath and gave rise to the leaf blade. The leaf

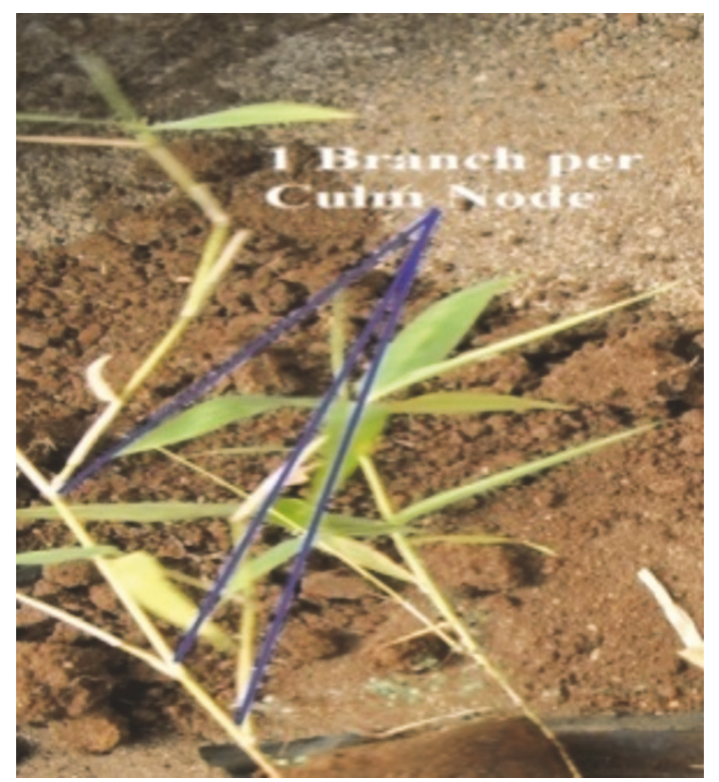

FIGURE 2: The branching pattern of O. abyssinica seedlings at each culm node (source: photo taken by Tinsae Bahru).

blade is attached to the culm sheath with a very small petiole. Leaves shaded during dry and hot season (December to February) and new leaves were developed and appeared green thereafter. A total number of 82 and 53 leaves were recorded in Sherkole and Pawe provenance, respectively. By contrast, the minimum number of leaves recorded in Pawe provenance was 10, while it was 5 for Sherkole. A large number of leaves were counted in Sherkole provenance with a mean value of $30.22 \pm 14.40$ than Pawe provenance $(25.47 \pm 10.87)$ (Table 3$)$. The result also showed a significant variation $(\mathrm{P}<0.05)$ in number of leaves between provenances.

3.2.4. Number and Length of Rhizomes. Practical observation on morphological structure of $O$. abyssinica seedlings was conducted during uprooting of each seedling. Removal of the soil from rhizomes and associated roots indicated that the root system (rhizomes and associated roots) was well established into the surrounding soil within the polyethylene pots. The rhizome bud developed from the mother culm base followed by the development of rhizome from the rhizome bud. Practical observation confirmed that rhizomes were connected to the base of mother culm on opposite side with a 
TABLE 4: Mean values of seedlings Biomass estimation between two O. abyssinica provenances ( $\mathrm{n}=30$, mean \pm SD).

\begin{tabular}{lcccccccc}
\hline Provenance & $\begin{array}{c}\text { Leaf fresh } \\
\text { weight }(\mathrm{g})\end{array}$ & $\begin{array}{c}\text { Culm fresh } \\
\text { weight }(\mathrm{g})\end{array}$ & $\begin{array}{c}\text { Root fresh } \\
\text { weight }(\mathrm{g})\end{array}$ & $\begin{array}{c}\text { Root-to-Shoot } \\
\text { Ratio }\end{array}$ & $\begin{array}{c}\text { Leaf dry } \\
\text { weight }(\mathrm{g})\end{array}$ & $\begin{array}{c}\text { Culm dry } \\
\text { weight }(\mathrm{g})\end{array}$ & $\begin{array}{c}\text { Root dry } \\
\text { weight }(\mathrm{g})\end{array}$ & $\begin{array}{c}\text { Root-to-Shoot } \\
\text { Ratio }\end{array}$ \\
\hline Pawe & $2.60 \pm 0.98$ & $2.90 \pm 1.51$ & $13.63 \pm 6.84$ & $2.69 \pm 1.15$ & $1.83 \pm 0.68$ & $1.90 \pm 0.95$ & $9.30 \pm 4.80$ & $2.70 \pm 1.35$ \\
Sherkole & $3.15 \pm 1.05$ & $3.03 \pm 1.41$ & $12.60 \pm 8.42$ & $1.99 \pm 0.76$ & $2.41 \pm 0.80$ & $2.48 \pm 1.11$ & $9.02 \pm 6.16$ & $1.77 \pm 0.67$ \\
t-value & 2.122 & 0.344 & 0.522 & 2.784 & 3.029 & 2.206 & 0.194 & 3.370 \\
Sig. & 0.038 & 0.732 & 0.604 & 0.007 & 0.004 & 0.031 & 0.847 & 0.002 \\
\hline
\end{tabular}

short-neck and finally formed clumps (Figure 1). From each rhizome nodes, 2-7 new rhizome roots were emerged as primary and secondary roots and established in the surrounding soil. At the same time, our observation demonstrated that at the base of the newly emerged Bamboo shoots many adventitious roots (culm roots) developed at the base of the mother culm. Sherkole provenance had slightly more number of rhizomes than Pawe. Such changes in rhizome number also causes a significant variation $(\mathrm{P}<0.001)$ between provenances (Table 3). Similarly, O. abyssinica seedlings possessed longer rhizomes that stretched in length between 9 and $50 \mathrm{~cm}$. But, seedlings from Pawe provenance recorded longer rhizomes than Sherkole provenance. The mean values of Pawe and Sherkole provenances were 31.80 and $28.67 \mathrm{~cm}$ long, respectively. Yet, no significant difference was recorded $\left(\mathrm{t}_{(179)}=1.70\right.$, $\mathrm{P}=0.095$ ) in length of rhizome between provenances.

3.3. Effects of Provenance on Total Seedlings Biomass Estimation. Collected data on total biomass estimation of $O$. abyssinica seedlings at laboratory (i.e., fresh and dry weights of shoot and root) were presented in Table 4.

3.3.1. Leaf Biomass Estimation. Leaf biomass comprised the leaves and young buds or twigs after separated from culm and branches of each $O$. abyssinica seedling. The young buds from branches and apical parts of the shoot were also included since they possess chlorophyll due to their green appearance and have a photosynthetic potential. Collected data at laboratory asserted that the weight of fresh leaves from each seedling ranged from 0.77-5.42 $\mathrm{g}$ between provenances (Table 4). The oven dried sample, in turn, weighed 0.6$3.88 \mathrm{~g}$. Larger fresh and dry leaf weights were recorded in Sherkole provenance than Pawe provenance. Such result also confirmed by the statistical t-test in that there was variation $(\mathrm{P}<0.05)$ between provenances in leaves weight before or after the dry oven test. These total mean values of fresh and dry leaf weights of Sherkole provenance were 3.15 and $2.41 \mathrm{~g}$, respectively.

3.3.2. Culm Biomass Estimation. Once the leaves and young buds separated from shoot in each seedling, the culm and branches made ready and weighed together. Analysis of laboratory data reported that the minimum fresh culms weighed $0.57 \mathrm{~g}$, while the maximum was $6.57 \mathrm{~g}$. Similarly, the minimum and maximum dry culms weight ranged from 0.49-5.16 g, respectively. Sherkole provenance had better culms biomass weight with a mean value of $3.03 \mathrm{~g}$ for fresh weight and $2.48 \mathrm{~g}$ for dry weight (Table 4 ). But, the variation between provenances was significant $(\mathrm{P}<0.05)$ for dry culms weight, while there was no such trend in fresh weight samples.

3.3.3. Root Biomass Estimation. Root biomass estimation in this study was based on each seedling underground root system. The root system comprised the mother culm base, culm roots, rhizomes as well as rhizome roots. Data analysis on $O$. abyssinica root biomass estimation indicated that the highest fresh and dry weights were recorded compared with other shoot parts (culms or leaves). The amount of water held in the root system was contributed for this additional weight gain. Accordingly, freshly collected root system weighed the least and the largest values of 3.23 and $47.45 \mathrm{~g}$ in $O$. abyssinica seedlings, respectively. The dry root weight also comprised from 2.07 up to $34.52 \mathrm{~g}$ weights after dry-oven record. Seedlings of Pawe provenance had higher weight gain with a mean value fresh and dry weights of 13.63 and 9.30, respectively (Table 4). However, this root fresh and dry weight variation was not significant $(\mathrm{P}<0.05)$ between provenances. Furthermore, the underground $O$. abyssinica seedlings biomass was $68.8 \%$ and $65.5 \%$ in fresh and dry biomass weights, respectively, out of the total biomass.

3.3.4. Root-to-Shoot Ratio. Root-to-shoot ratio of $O$. abyssinica seedlings is expressed as the ratio of the underground (root) weight to the aboveground (shoot) weight of seedlings as presented in Table 4. It measures the overall health, i.e., the growth and development of seedlings. Laboratory result asserted that O. abyssinica seedlings fresh root-to-shoot ratio $(2.69 \pm 1.15)$ was lower than the dry ratio $(2.70 \pm 1.35)$ for Pawe provenance. But, this ratio was the reverse in Sherkole provenance, where the fresh root-toshoot ratio $(1.99 \pm 0.76)$ was larger than the dry ratio $(1.77 \pm$ $0.67)$. In contrast, both the fresh and dry root-to-shoot ratio of Pawe provenance was higher than Sherkole provenance. This is because of the higher root biomass weight in Pawe provenance as compared to Sherkole.

\section{Discussion}

A two-year research study at green house on O. abyssinica seedlings found out that seedlings were grown up to a height of $102 \mathrm{~cm}$ and around $0.5 \mathrm{~mm}$ RCD. The seedlings size for field establishment further demonstrated that the average height was $64 \mathrm{~cm}$, which is successfully achieved beyond the recommended value. But, the average RCD was $0.26 \mathrm{~mm}$, i.e., far less than the required size. Previous studies on plantable size of $O$. abyssinica seedlings at nursery reported 
that its height ranges from 40 to $50 \mathrm{~cm}$ [9], while the RCD of sympodial Bamboo seedlings is above $0.5 \mathrm{~cm}[24,25]$. The pachymorph rhizome type of $O$. abyssinica seedlings found out in this study is similarly reported by earlier researchers $[3,4,10,13]$. This is because such type of rhizome is characterized by the formation of clumps and has a short rhizome neck emerged from the mother culm base $[3,13]$. In addition, earlier studies on sympodial Bamboo reported that this rhizome type is mostly seen in tropical Bamboo [26]. A slightly higher survival rate of $O$. abyssinica seedlings at Pawe provenance (91\%) than Sherkole provenance $(90 \%)$ revealed that the seed sources further contributed to the successful survival rate of seedlings at green house. Former research conducted by [11] assured that Pawe provenance has better seed germination and seed weight than Sherkole provenance. Nevertheless, both provenances further have higher potential in producing viable and vigour seeds [12]. In any case, these two research outputs suggested that provenance variation has some contribution for both producing viable and vigor seeds at laboratory and better survival rate and growth performance of $O$. abyssinica seedlings at green house. This, further, plays a key role in production of best quality and required number of seedlings for intended plantation development goals at field. Such variation might enhance both the early survival and growth performance and hence the adaptation potential of a suitable provenance [27]. Earlier research outputs also support this study, where the variation of provenances has an effect on the seedlings survival rate and growth performances on various tree species [28-30]. This is because species widely distributed in a broad geographical range are generally associated with provenance variation in both morphological and physiological attributes [16, 27]. Savill et al. [16] defined the term provenance as the original geographic source of the seed. As a result, the difference in provenances is associated with a variation in their adaptation ability at a particular area. According to the study this is because there is a limited probability of inbreeding between provenances and thereby causes always genetic variations. Therefore, during plantation development of $O$. abyssinica seedlings selection of provenances to produce high quality and large number of seedlings should be considered so as to maximize the survival rate of seedlings and minimize the mortality rate (up to $10 \%$ ) of seedlings. This research output is again supported by Mamo and Mihretu [23] as well as Shumi et al. [28], where the long-term yield of plantation per unit area can be affected by the mortality or survival rate of seedlings.

The morphology of $O$. abyssinica seedlings at green house demonstrated that some culms possessed one or more number of branches developed from the main culm node. These branches were attached in alternate positions on the culm node. Such branching pattern on a culm node is an important criterion for Bamboo species identification and taxonomy [26]. The presence of sheath scar in each culm node on $O$. abyssinica seedlings are also similarly mentioned by other related study on Bamboo morphology [31]. Furthermore, the semi-solid feature of culm internodes during the seedling stage is changed to solid culm internodes after maturity $[3,4,10,13]$. This especial feature makes the species more preferable in construction and other related uses even as compared to the Ethiopian indigenous Highland Bamboo (Arundinaria alpina (K. Schum.)). There was almost no considerable difference in culm diameter growth (0.1$0.5 \mathrm{~mm}$ RCD) was observed as compared to culm height. This might be due to the absence of cambium and radial tissues in Bamboo [31] unlike stem diameter of trees. As a result, Bamboo undergoes primary growth but not secondary growth $[26,31]$. Higher seedlings RCD growth, in turn, might be helpful in better physical support and establishment of the seedlings. Larger culm height and number of culms per clump in Sherkole provenance associated with larger RCD values in Pawe provenance further could be contributed for better physical support and field establishment, survival rate and higher growth performance of seedlings. Some of the pervious works that support this result include Florence [27], Shumi et al. [28], Bahru et al. [29, 30], Alem et al. [32], Andivia et al. [33], Fredrick et al. [34], and Terefe et al. [35]. A large number of leaves were counted in Sherkole provenance as compared to Pawe provenance. Such development of large number of leaves per seedlings is contributed to large surface area for light absorption [36, 37]. This further enhances higher efficiency of photosynthesis within leaves and resulted in higher growth rate of seedlings [3638]. Therefore, Sherkole provenance is suggested for raising seedlings at green house due to its larger culm height, number of culms per clump, and number of leaves and hence better adaptation potential. Likewise, Sherkole provenance had slightly more number of rhizomes, while Pawe provenance recorded longer rhizomes roots. Such large mass and longer rhizomes and rhizomes roots might increase the surface area for efficient absorption of water and nutrients [39]. It also provides a firm physical support for seedlings as well as a means of vegetative reproduction system [40]. Furthermore, the normal physiological function of fine roots and leaves is directly related [41]. Considering the study this is because the finest roots of a tree are connected to the leaves by an elaborate system of larger transport roots, stems, branches and twigs.

Biomass estimation of leaf weights indicated that almost two-third or $75 \%$ of the water retained in O. abyssinica seedlings was lost after dried in dry oven. Hence, this study further assured that most of the weight of leaves was occupied by water, which might play a significant role for the process of photosynthesis and transpiration. Consequently, this further enhances higher efficiency of photosynthesis within leaves and resulted in higher growth rate of seedlings [36-38]. Sherkole provenance had better culms biomass weight than Pawe provenance. Nath et al. [42] reported that the aboveground Bamboo stand biomass and carbon storage potential was $121.51 \mathrm{t} / \mathrm{ha}$ and $61.05 \mathrm{t} / \mathrm{ha}$, respectively. Out of this, the author reported that the highest stand biomass was produced by culms (86\%), branch (10\%) and leaf (4\%). Finally, $68.8 \%$ of underground O. abyssinica seedlings was fresh biomass suggested that Bamboo are important in underground high biomass production and carbon sink. Likewise, the total aboveground biomass of Bambusa bambos is almost twice that of the Eucalyptus clones [43]. The higher productivity, the fastest growth potential and short rotation 
TABLE 5: Provenances of O. abyssinica seedlings suitability index evaluation.

\begin{tabular}{|c|c|c|c|c|c|c|c|c|c|c|c|c|}
\hline \multirow[b]{2}{*}{ Provenance } & \multirow[b]{2}{*}{$\begin{array}{c}\text { Survival } \\
\text { rate }\end{array}$} & \multicolumn{6}{|c|}{ Scoring out of 10 points } & \multirow[b]{2}{*}{$\begin{array}{c}\text { Leaf } \\
\text { fresh } \\
\text { weight }\end{array}$} & \multirow[b]{2}{*}{$\begin{array}{c}\text { Culm } \\
\text { fresh } \\
\text { weight }\end{array}$} & \multirow[b]{2}{*}{$\begin{array}{c}\text { Root } \\
\text { fresh } \\
\text { weight }\end{array}$} & \multirow[b]{2}{*}{$\begin{array}{c}\text { Total } \\
\text { scores }\end{array}$} & \multirow[b]{2}{*}{ Rank } \\
\hline & & Height & RCD & $\begin{array}{l}\text { No of } \\
\text { culms }\end{array}$ & $\begin{array}{l}\text { No of } \\
\text { leaves }\end{array}$ & $\begin{array}{l}\text { Rhizome } \\
\text { length }\end{array}$ & $\begin{array}{c}\text { No of } \\
\text { clustered } \\
\text { rhizome }\end{array}$ & & & & & \\
\hline Pawe & 9.1 & 6.1 & 0.026 & 0.24 & 2.5 & 3.2 & 0.4 & 0.26 & 0.29 & 1.4 & 23.52 & $2^{\text {nd }}$ \\
\hline Sherkole & 9.0 & 6.7 & 0.025 & 0.32 & 3.0 & 2.9 & 0.6 & 0.32 & 0.30 & 1.3 & 24.47 & $1^{\text {st }}$ \\
\hline
\end{tabular}

TABLE 6: Correlation matrix of O. abyssinica seedlings growth and Biomass variables for Sherkole provenance (Pearson coefficients, two-tailed, and $\mathrm{n}=30$ ).

\begin{tabular}{|c|c|c|c|c|c|c|c|c|}
\hline Variables & Height & RCD & $\begin{array}{c}\text { Height } / \mathrm{RCD} \\
\text { ratio }\end{array}$ & $\begin{array}{l}\text { Rhizome } \\
\text { length }\end{array}$ & $\begin{array}{l}\mathrm{R} / \mathrm{S} \text { Biomass } \\
\text { ratio }\end{array}$ & $\begin{array}{c}\text { Seedlings total } \\
\text { Biomass }\end{array}$ & $\begin{array}{c}\text { Shoot } \\
\text { Biomass }\end{array}$ & $\begin{array}{c}\text { Root } \\
\text { Biomass }\end{array}$ \\
\hline Height & 1 & & & & & & & \\
\hline RCD & .333 & 1 & & & & & & \\
\hline Height/RCD ratio & $.366 *$ & $-.695 * *$ & 1 & & & & & \\
\hline Rhizome length & .207 & .279 & -.094 & 1 & & & & \\
\hline $\mathrm{R} / \mathrm{S}$ Biomass ratio & -.197 & $-.756 * *$ & $.657 * *$ & .358 & 1 & & & \\
\hline $\begin{array}{l}\text { Seedlings total } \\
\text { Biomass }\end{array}$ & $.616 * *$ & $.461 *$ & .000 & $.576 * *$ & -.105 & 1 & & \\
\hline Shoot Biomass & $.504 * *$ & $.527 * *$ & -.123 & $.485 * *$ & -.201 & $.805 * *$ & 1 & \\
\hline Root Biomass & $.598 * *$ & $.409 *$ & .031 & $.565 * *$ & -.067 & $.987 * *$ & $.706 * *$ & 1 \\
\hline
\end{tabular}

$* *$. Correlation is significant at the 0.01 level.

*. Correlation is significant at the 0.05 level.

of Bamboo over the Eucalyptus species confirm that Bamboo are a potential promising species for large and small scale plantation development. The fresh root-to-shoot ratio of Pawe provenance (2.48) was higher than Sherkole provenance (2.04). Therefore, the greater root-to-shoot ratio in Pawe provenance could be related to the limited availability of water and nutrients supply to the leaves. As a result, more energy is shifted from the shoot to the roots and thereby the growth and development of the root system becomes more proliferated and flourished deep into the soil. According to Taiz and Zeiger [37] root-to-shoot biomass ratio appears to be governed by functional balance between water uptake by the root and photosynthesis by the shoot. In one hand, a shoot will tend to grow until water uptake by the roots becomes limiting to further growth. In contrast to shoot growth, roots tend to grow until their demand for photosynthesis products exceeds from the shoot supply $[36,37]$. But such plant functional balance will be affected by the water deficits in the soil. As the water supply to shoot becomes limited the process of photosynthesis is affected. Eventually, in order to reverse the continuous supply of water to leaves more energy is allocated to the root system so as to enhance further root growth into deeper soil for the absorption of enough water [36, 37, 44, 45].

In general, provenance variation on early survival rate and growth performance of $O$. abyssinica seedlings was evaluated using suitability index (Table 5). Accordingly, Sherkole provenance (24.47) had better suitability index than Pawe provenance (23.52) for raising seedlings at green house. This study was in agreement with a research carried out by Mamo and Mihretu [23] on provenances of Juniperus procera.
Therefore, Sherkole provenance is promising to select as seed sources and raising seedlings.

At the same time, considering its suitability for raising quality seedlings at green house, Sherkole provenance growth and Biomass parameters were further evaluated for the correlation analysis (Table 6). With this, seedling height had a strong positive correlation with seedlings total Biomass ( $r=$ 0.616 ; $p<0.01$ ). In turn, the highest significant negative correlation was observed between seedling RCD with both rootto-shoot Biomass ratio \& height to RCD ratio ( $r=-0.756 \&-$ 0.695; $p<0.01$ ). Meanwhile, shoot Biomass \& root Biomass; seedlings total Biomass \& rhizome length as well as root-toshoot Biomass ratio \& height to RCD ratio were also strongly correlated to each other $(p<0.01)$. On the contrary, except for height and root-to-shoot Biomass ratio and RCD \& seedlings total Biomass, which had a significant correlation at $p<0.05$, there was no significant correlation $(p<0.05)$ between other morphological variables. Collectively, our result was closely consistent with Tian et al. [46], who reported that seedling height has a highly significant positive correlation $(p<0.01)$ with other morphological and Biomass variables. Therefore, such correlation of morphological variables might be used to evaluate seedling quality at green house and thereby forecast its performance at field.

Based on this result, linear regression equations were developed for six main variables that strongly correlated to each other (Figure 3 ). The equation was written as $y=a+b x$, where $y$ is a dependent variable, $x$ is a predictor variable for the linear regression model, $a$ is the $y$-intercept at $x=0$ and $b$ is the slope of the regression equation. Consequently, the highest values of coefficient of determination $\left(\mathrm{R}^{2}\right)$ was 

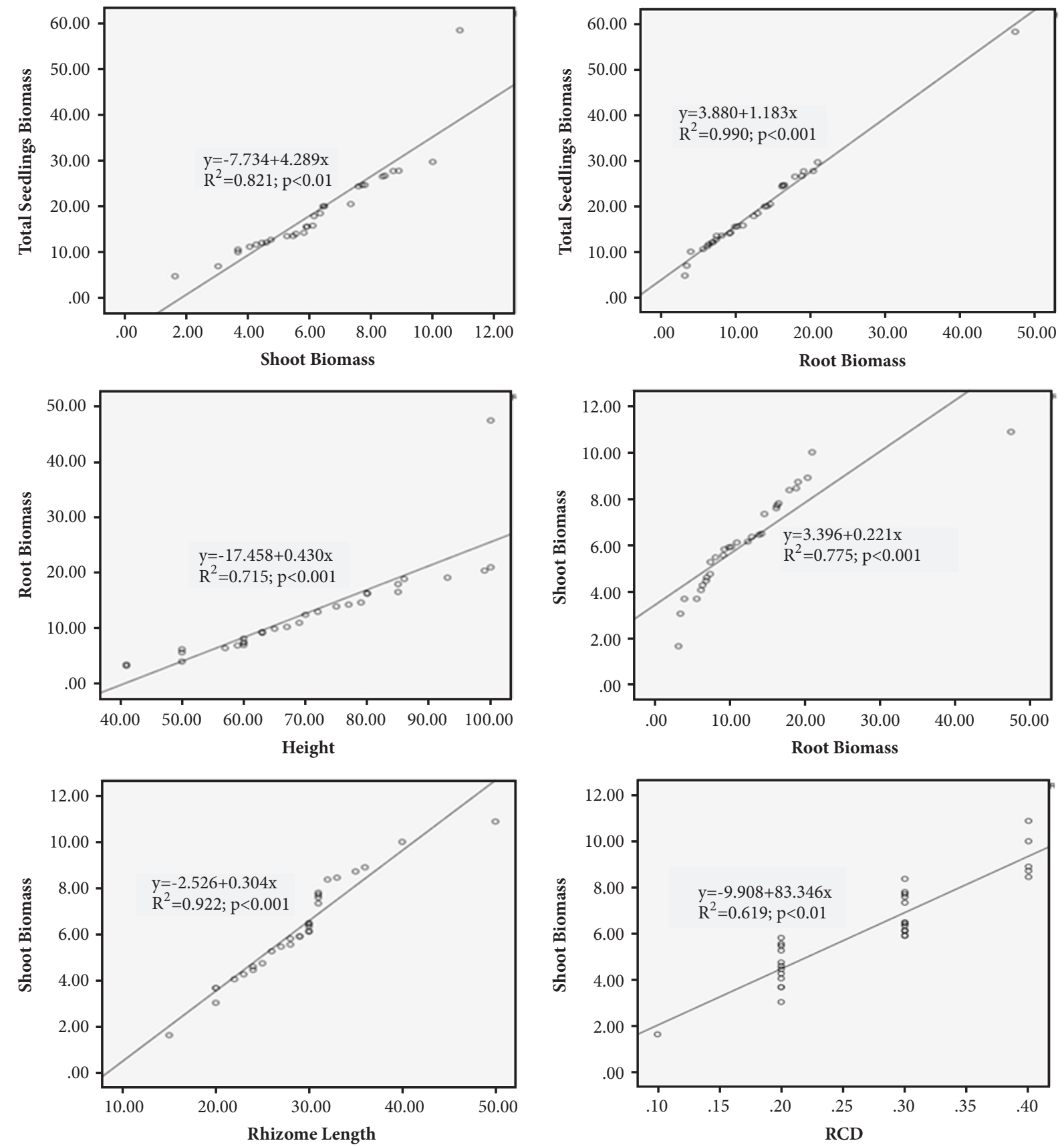

FIGURE 3: Relationship between O. abyssinica seedlings growth and Biomass variables and the developed linear regression equations and coefficient of determination $\left(\mathrm{R}^{2}\right)$ that indicated the strength of regression model.

recorded in the developed linear regression models $\left(\mathrm{R}^{2}=0.715\right.$ to 0.990 ), which means at least $71.5 \%$ of the total variation in the dependent response variable was explained by the linear regression model and hence the strength of the model. Moreover, the larger correlation coefficient $(\mathrm{R}=0.619$ to 0.995 ) and Beta values (0.787 to 0.995) further indicated the strong linear relationships between the growth and Biomass variables. The strongest linear correlation among the six pairs of variables was illustrated by root Biomass with total seedlings Biomass. On the contrary, shoot Biomass and RCD and the weakest linear association among the variables. At the same time, seedlings height had a relatively strong association with root Biomass, while RCD had strong correlation with shoot Biomass. Shoot and root Biomass in turn, had strong association with other variables. Therefore, the strong linear association of height and RCD with all other variables assured that seedling quality at green house was evaluated only with height and RCD data without considering other variables, which is more cost effective and time saving process. 


\section{Conclusion and Recommendation}

The present study found out that Pawe provenance had higher survival rate (91\%) than Sherkole provenance $(90 \%)$. Therefore, the insignificant provenance variation further suggests that both provenances (Pawe and Sherkole) are recommended for raising large number of $O$. abyssinica seedlings at green house with higher survival potential. Except higher RCD, rhizomes length, fresh and dry roots weights, and higher seedlings parameters were recorded in Sherkole provenance. Biomass estimation for both provenances further indicated that weight of fresh leaves, culms, and rhizome system ranged from 0.77 to $5.42,0.57$ to 6.57 , and 3.23 to $47.45 \mathrm{~g}$, respectively. Nevertheless, significant variation $(\mathrm{P}<0.05)$ between provenances was observed in RCD, rhizomes length, weight of fresh culms, and fresh \& dry root system. Fresh root-to-shoot ratio $(1.99 \pm 0.76)$ was larger than the dry ratio $(1.77 \pm 0.67)$ for Sherkole provenance. But, both the fresh and the dry root-to-shoot ratio of Pawe provenance were higher than Sherkole provenance. In Sherkole provenance, seedling height had a strong positive correlation with seedlings total Biomass $(r=0.616 ; p<0.01)$. However, the highest significant negative correlation was observed between seedling RCD with both root-to-shoot Biomass ratio \& height to RCD ratio ( $r=-0.756 \&-0.695 ; p<0.01)$. Overall, Sherkole provenance had better suitability index (24.47) than Pawe provenance for raising seedlings at CEE-FRC green house. However, Pawe provenance is further recommended as a promising alternative for seedlings production especially if there is a scarcity of seeds from Sherkole provenance. Seedlings growth parameters (height and RCD) were positively and significantly correlated with Biomass variables and hence could be considered as better evaluation criteria for seedling quality at green house. Lastly, this green house result might be not applicable at field establishment of O. abyssinica seedlings. Therefore, the provenance trial should be further carried out at field to evaluate the establishment, growth performance as well as adaptation potential and thereby select better provenance for future plantation development.

\section{Data Availability}

The data that support the findings of this study are available from Central Ethiopian Environment and Forest Research Center (CEE-FRC)/Ethiopian Environment and Forest Research Institute (EEFRI) but restrictions apply to the availability of these data, which were used under license for the current study, and so they are not publicly available. Data are however available from the corresponding author (Tinsae Bahru) upon reasonable request and with permission of Central Ethiopian Environment and Forest Research Center (CEE-FRC)/Ethiopian Environment and Forest Research Institute (EEFRI).

\section{Conflicts of Interest}

The authors declare no conflicts of interest.

\section{Authors' Contributions}

All authors had their own intellectual contribution towards the implementation of this research work and eventually to produce the full manuscript write up. Tinsae Bahru is the corresponding author of this manuscript. He mainly commented the project activity during the implementation of the activity, seed collection, processing and handling, established the experimental layout at laboratory and green house, data collection, entry, and analysis, wrote the full manuscript, and submitted the manuscript to the Journal and eventually incorporating all the given constructive comments by the reviewers. Berhane Kidane and Yigardu Mulatu were involved in writing the project activity.

\section{Acknowledgments}

The authors are grateful to CEE-FRC/EEFRI for the financial support and provision of necessary logistic facilities for the entire work. Sincere thanks also go to seed collectors from districts, seed processing room, tree seed laboratory, and nursery and cold room staffs of CEE-FRC/EEFRI for their invaluable contribution during the experiment as well as others who directly or indirectly offered their kind support.

\section{References}

[1] S. Phillips, "Poaceae (Gramineae)," in Flora of Ethiopia Volume 7, National Herbarium, I. Hedberg and S. Edwards, Eds., pp. 3-6, Biology Department, Science Faculty, Addis Ababa University, Addis Ababa, Ethiopia; Department of Systematic Botany, Uppsala University, Uppsala, Sweden, 1995.

[2] D. Ohrnberger, The Bamboo of the world, Elsevier, Amsterdam, The Netherlands, 1999.

[3] T. J. Meredith, Bamboo for Gardens, Timber Press, Portland, Oregon, U.S.A, 2001.

[4] K. Embaye, "The indigenous Bamboo forests of Ethiopia: an overview," Ambio, vol. 29, no. 8, pp. 518-521, 2000.

[5] H. Huojin, Monograph on Bamboo Resources and Utilization Techniques. Ministry of Environment and Forest, Mishqen Printing Press, Addis Ababa, Ethiopia, 2014.

[6] Y. Zhao, D. Feng, D. Jayaraman et al., "Bamboo mapping of Ethiopia, Kenya and Uganda for the year 2016 using multitemporal Landsat imagery," International Journal of Applied Earth Observation and Geoinformation, vol. 66, pp. 116-125, 2018.

[7] S. Nune, "Short notes on Bamboo," in Kosso, A Quarterly Newsletter of the Ethiopian Foresters' Association, pp. 2-5, Ethiopian Foresters' Association (EFA), Addis Ababa, Ethiopia, 2001.

[8] N. Bystriakova, V. Kapos, and I. Lysenko, Bamboo Biodiversity: Africa, Madagascar and the Americans. UNEP-WCMC/INBAR, 2004.

[9] J. Zehui, F. Benhua, C. Xuhe et al., Eds., Bamboo and Rattan in the World, China Forestry Publishing House, Beijing, China, 2007.

[10] UNIDO, Bamboo Cultivation Manual. Guidelines for Cultivating Ethiopian Lowland Bamboo, Eastern Africa Bamboo Project, United Nations Industrial Development Organization (UNIDO), 2009. 
[11] T. Bahru, Y. Mulatu, and B. Kidane, "Germination Ecology of Arundinaria alpina (K. Schum.) and Oxytenanthera abyssinica (A. Rich.) Munro Seeds: Indigenous Bamboo Species in Ethiopia," International Journal of Biodiversity, vol. 2015, Article ID 323128, 8 pages, 2015.

[12] T. Bahru, B. Kidane, A. Araya et al., "Effects of Germination Sites on Germination Percentage, Germination Energy and Germination Value of Lowland Bamboo Seeds, in Forestry and Forest Products in Ethiopia: Technologies and Issues," in Proceedings of the National Workshop on Forestry Research Technologies Dissemination, W. Tadesse, G. Desalegn, and A. Yirgu, Eds., pp. 85-95, Hiruy Hall, EIAR, Addis Ababa, Ethiopian Institute of Agricultural Research (EIAR), Addis Ababa, Ethiopia, May, 2012.

[13] B. N. Kigomo, Guidelines for Growing Bamboo. KEFRI Guideline Series: No. 4, Kenya Forestry Research Institute (KEFRI). Downtown Printing Works Ltd., Nairobi, Kenya, 2007.

[14] E. Kelbessa, T. Bekele, A. Gebrehiwot et al., A socio-economic case study of the Bamboo sector in Ethiopia: An analysis of the production-to-consumption system, Addis Ababa, 2000.

[15] FAO, World Bamboo Resources: A thematic study prepared in the framework of the Global Forest Resources Assessment 2005. Non-Wood Forest Products No. 18, Food and Agriculture Organization, Rome Italy, 2007.

[16] P. Savill, J. Evans, D. Auclair et al., Plantation Silvicultue in Europe, Oxford University Press, New York, NY, USA, 1997.

[17] H. Shiferaw, Irrigation potential evaluation and crop suitability analysis using GIS and Remote Sensing technique in Beles sub basin, Beneshangul-Gumez Region [MSc. Thesis], Addis Ababa University, Addis Ababa, Ethiopia, 2007.

[18] B. Alemu, E. Garedew, Z. Eshetu et al., "Land Use and Land Cover Changes and Associated Driving Forces in North Western Lowlands of Ethiopia," International Research Journal of Agricultural Science and Soil Science, vol. 5, no. 1, pp. 28-44, 2015.

[19] FAO, Forest Genetic Resources Information. No. 4. Forest Occasional Paper (1975/1), Food and Agriculture Organization, Rome, Italy, 1975.

[20] FAO, A guide to forest seed handling with special reference to the tropics, FAO Forestry Paper 20/2, Food and Agriculture Organization, Danida Forest Seed Centre, Copenhagen, Denmark, 1985.

[21] C. C. Baskin and J. M. Baskin, Seeds: Ecology, Biogeography and Evolution of Dormancy and Germination, School of Biological Sciences, University of Kentucky, Lexington, Ky, USA. Academic Press, New York, NY, USA, 2001.

[22] H. T. Hartmann and D. E. Kester, Plant Propagation: Principles and Practices, Prentice-Hall International, Upper Saddle River, NJ, USA, 4th edition, 1983.

[23] N. Mamo and M. Mihretu, "Provenance effect on early survival and growth performance of Juniperus procera at Jibli, Awi zone," Ethiopian Journal of Natural Resource, vol. 7, pp. 203-217, 2005.

[24] S. Fan and Z. Gao, "Establishment and management of Bamboo plantations in China," in Bamboo and Rattan in the World, J. Zehui, F. Benhua, C. Xuhe et al., Eds., pp. 40-51, China Forestry Publishing House, Beijing, China, 2007.

[25] F. Maoyi, X. Jinzhong, Z. Benzhi et al., Technical manual on sympodial Bamboos cultivation, China Forestry Publishing House, Beijing, China, 2007.
[26] Y. Ding, Botanical Characteristics of Bamboo, in Bamboo and Rattan in the World, J. Zehui, F. Benhua, C. Xuhe et al., Eds., China Forestry Publishing House, Beijing, China, 2007.

[27] R. G. Florence, Ecological and Silviculture of Eucalypt forests, The Australian National University, Department of forestry, CSIRO, Australia, 1996.

[28] G. Shumi, Y. Seyoum, W. Melak et al., "Provenance Effects on Early Survival and Growth of Juniperus procera at Kulumsa, Arsi Zone, in Forestry and Forest Products: Technologies and Issues," in Proceedings of the National Workshop on Forestry Research Technologies Dissemination, pp. 33-40, Ethiopian Institute of Agricultural Research (Hiruy Hall, EIAR, Addis Ababa, Ethiopia), Addis Ababa, Ethiopia, May 2012.

[29] T. Bahru, A. Eshete, Y. Mulatu et al., "Effects of provenance on seed germination, early survival and growth performance of Ziziphus spina-christi (L) Desf.: A multipurpose wild fruit species in Ethiopia, in Forest and Environment Research: Technologies and Information," in Proceedings of the 1st Technology Dissemination Workshop, M. Alebachew, G. Desalegn, W. Tadesse et al., Eds., pp. 375-398, Ethiopian Environment and Forest Research Institute, Addis Ababa, Ethiopia, 2017, Adama, Ethiopia, November, 2015.

[30] T. Bahru, A. Eshete, Y. Mulatu et al., "Effect of provenances on seed germination, early survival and growth performance of Tamarindus indica L. in Ethiopia: a key multipurpose species," Advances in Materials Science and Engineering: An International Journal (MSEJ), vol. 1, no. 1, pp. 1-8, 2014.

[31] B. Fei and H. Ren, Structure and properties of Bamboo, in Bamboo and Rattan in the World, J. Zehui, F. Benhua, C. Xuhe et al., Eds., China Forestry Publishing House, Beijing, China, 2007.

[32] S. Alem, W. Tadesse, P. Guzman et al., "Provenance variation in germination and seedling growth of Eucalyptus globules, in Eucalyptus species management, history, status and trends in Ethiopia," in Proceedings of the conference on Eucalyptus Species Management, History, Status and Trends in Ethiopia, L. Gil, W. Tadesse, E. Tolosana et al., Eds., pp. 240-245, Ethiopian Institute of Agricultural Research, Hiruy Hall, EIAR, Addis Ababa, Ethiopia, September 2010.

[33] E. Andivia, M. Fernández, J. Vázquez-Piqué, and R. Alejano, "Two provenances of Quercus ilex ssp. ballota (Desf) Samp. nursery seedlings have different response to frost tolerance and autumn fertilization," European Journal of Forest Research, vol. 131, no. 4, pp. 1091-1101, 2012.

[34] C. Fredrick, C. Muthuri, K. Ngamau et al., "Provenance variation in seed morphological characteristics, germination and early seedling growth of Faidherbia albida," Journal of Horticulture and Forestry, vol. 7, no. 5, pp. 127-140, 2015.

[35] R. Terefe, D. Samuel, M. Sanbato et al., "Adaptation and Growth Performance of Different Lowland Bamboo Species in Bako, West Shoa, Ethiopia," Journal of Natural Sciences, vol. 6, no. 9, pp. 61-65, 2016.

[36] H. Lambers, F. S. Chapin III, and T. L. Pons, Plant Physiological Ecology, Springer, New York, NY, USA, 1998.

[37] L. Taiz and E. Zeiger, Plant Physiology, Sinauer Associates Inc., Publishers, Sunderland, Massa, USA, 5th edition, 2010.

[38] R. F. Evert and S. E. Eichhorn, Raven: Biology of Plants, W. H. Freeman and Company Publishers, New York, NY, USA, 8th edition, 2013.

[39] N. Silvana, "Understanding root systems to improve seedling quality," HortTechnology, vol. 8, no. 4, pp. 544-549, 1998. 
[40] J. Xiao, B. Zhou, and X. Shao, Basis of Bamboo Forest Silviculture, in Bamboo and Rattan in the World, J. Zehui, F. Benhua, C. Xuhe et al., Eds., China Forestry Publishing House, Beijing, China, 2007.

[41] T. O. Perry, "The ecology of tree roots and the practical significance thereof," Journal of Arboriculture, vol. 8, no. 8, pp. 197-211, 1982.

[42] A. Jyoti Nath, G. Das, and A. K. Das, "Above ground standing biomass and carbon storage in village bamboos in North East India," Biomass \& Bioenergy, vol. 33, no. 9, pp. 1188-1196, 2009.

[43] Y. Lou, Comprehensive benefits of Bamboo forests, in Bamboo and Rattan in the World, J. Zehui, F. Benhua, C. Xuhe et al., Eds., China Forestry Publishing House, Beijing, China, 2007.

[44] R. K. Sinha, Modern Plant Physiology, Alpha Science International Ltd., Pangbourne, England, 2004.

[45] S. G. Pallardy, Physiology of woody plants, Elsevier Inc., USA, 3rd edition, 2008.

[46] N. Tian, S. Fang, W. Yang, X. Shang, and X. Fu, "Influence of container type and growth medium on seedling growth and root morphology of Cyclocarya paliurus during nursery culture," Forests, vol. 8, no. 387, pp. 1-16, 2017. 

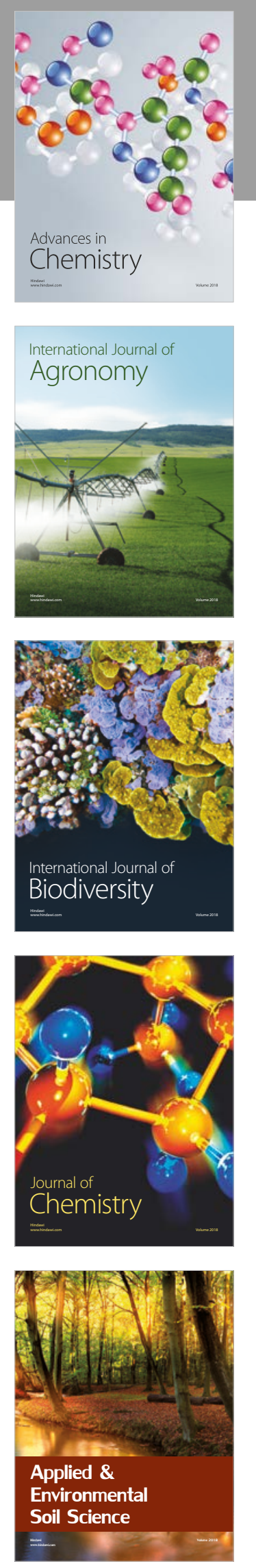

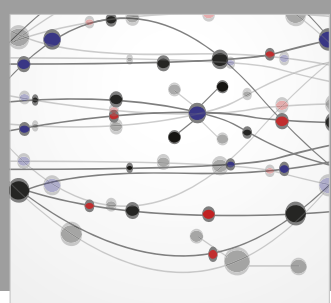

The Scientific World Journal

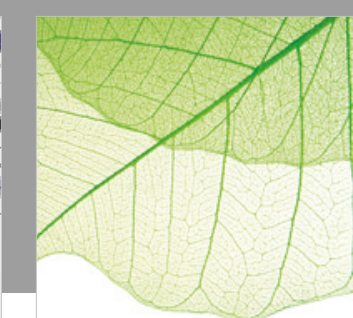

Journal of Botany

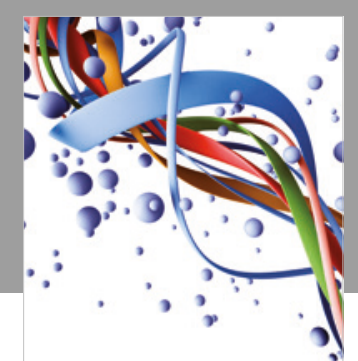

Scientifica

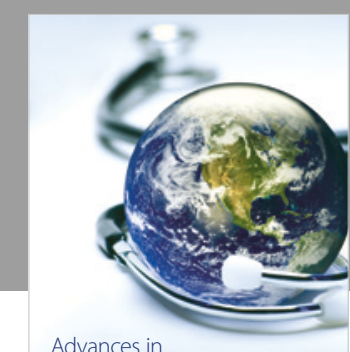

Public Health

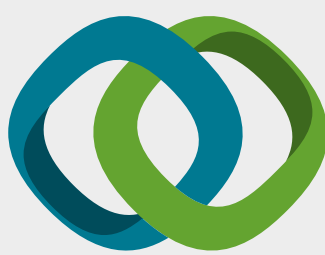

Hindawi

Submit your manuscripts at

www.hindawi.com
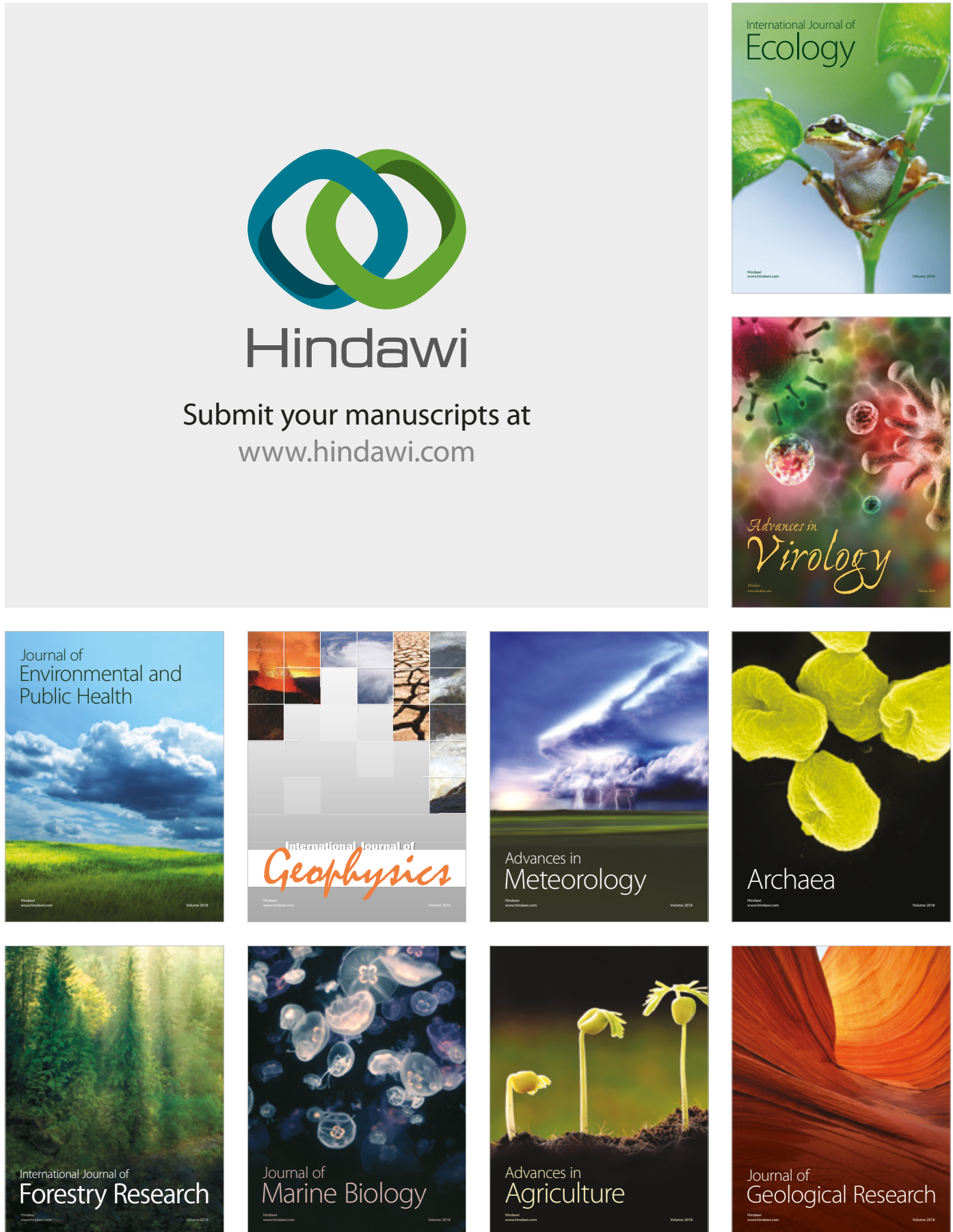

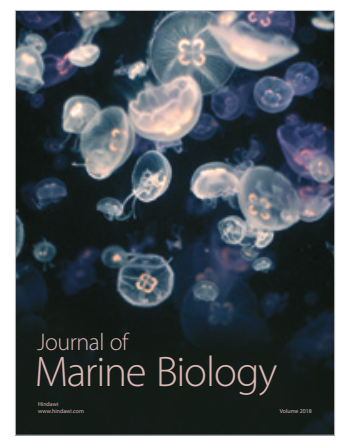

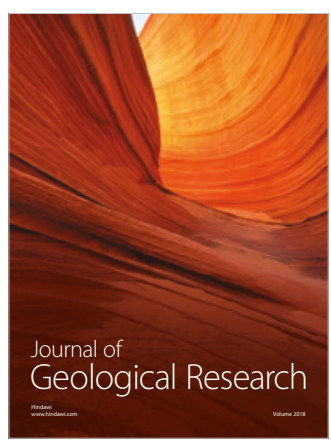

